\title{
Remesas de caudales españoles durante los primeros años del México independiente, 1821-1827
}

\author{
Jesús Ruiz de GoRdeJUELA URQuiJo \\ URJC - IAEAL \\ jesus@ruizdegordejuela.com
}

Recepción: 16 de junio de 2015 / Revisión: 3 de febrero de 2016

Aceptación: 4 de febrero de 2016 / Publicación: Diciembre de 2016

\begin{abstract}
RESUMEN
Este trabajo pretende reflejar una visión lo más completa posible sobre la salida de la plata mexicana de peninsulares durante los años comprendidos entre la independencia de México y la primera ley de expulsión de españoles. Para cumplir con este objetivo procuramos responder los siguientes interrogantes: ¿cómo?, ¿cuándo?, ¿cuánto?, ¿a dónde? y ¿por dónde? se produjo esta salida millonaria de pesos mexicanos propiedad de los españoles y, finalmente, ¿por qué la plata fue destinada a ciertas plazas europeas?
\end{abstract}

Palabras clave: Plata, remesas, México, España, Inglaterra y Francia, siglo XIX.

\section{Remittances of Spanish Fortunes during the First Years of Mexican Independence, 1821-1827}

\begin{abstract}
This study attempts to provide as complete a vision as possible, of the shipment of Mexican silver belonging to peninsular Spaniards, in the years between the independence of Mexico and the first law regulating the expulsión of Spaniards. In order to comply with this objective we attempt to respond to the following questions: How, when, how much, to where, and through where, was the shipment of millions of Mexican pesos, owned by Spaniards, carried out? Lastly, why was the silver destined to certain European cities?
\end{abstract}

Keywords: Silver, Remittances, Mexico, Spain, England and France, $19^{\text {th }}$ Century.

Sumario: 1. Introducción. 2. Veracruz, principal puerto de salida de caudales de México. 3. Londres, principal destino de la plata mexicana tras la independencia. 4. Llegada de caudales a España. 5. Burdeos y la plata mexicana. 6. Conclusiones. 7. Referencias bibliográficas. 


\section{INTRODUCCIÓN}

Aunque no se ha publicado ningún estudio general que verse sobre la salida de la plata americana propiedad de los españoles en estos años, algunos investigadores como Montserrat Gárate, Antonio Florencio Puntas y Àngels Solà presentaron interesantes trabajos referentes a este hecho en las regiones periféricas vasca, andaluza y catalana ${ }^{1}$. Asimismo, otros pocos han publicado artículos biográficos o estudios de inventarios de bienes de destacados personajes que se refugiaron en España tras las independencias, pero que en su mayor parte hacen referencia a fechas posteriores al periodo de nuestro estudio. En 2006 se presentó una ambiciosa investigación sobre los repatriados y sus capitales de México titulada La expulsión de los españoles de México y su destino incierto, 1821-1836, en donde se trataba el efecto de las leyes de expulsión de españoles de los años 1827 y 1829, priorizando más en el factor humano que en el económico. Transcurrida una década de esta investigación pretendemos aportar aspectos relevantes sobre este aspecto menos tratado como es la salida de caudales propiedad de españoles de México desde momentos antes a la independencia hasta la primera ley de expulsión de españoles dictada en diciembre de 1827.

Para poder argumentar este trabajo hemos realizado una búsqueda profunda y sistemática en archivos, en la prensa de la época, y en fuentes bibliográficas referentes a este tema y periodo. Además de lo anterior, nos hemos servido de la privilegiada documentación del archivo del comerciante vizcaíno, asentado en Cádiz, Francisco de Carranza, que nos ha permitido conocer, gracias a las cartas particulares a familiares, amigos y clientes cómo se vivió en primera persona la llegada de la plata y oro mexicana propiedad de los españoles repatriados ${ }^{2}$.

Las primeras referencias a la expatriación de plata en vísperas de la independencia de México nos la ofrece el historiador y político Lucas Alamán, quien informaba a finales de octubre de 1814 de la salida de la ciudad de México de un convoy «conduciendo reales y gran número de familias de europeos que emigraban para España» ${ }^{3}$, y cuya salida el virrey Calleja intentó evitar, al temer que la fuga de tan importantes capitales pudieran producir un grave trastorno al comercio y no pudiera servir al gobierno virreinal ${ }^{4}$. La conducta llegó a Jalapa el 18 de noviembre, en donde una tercera parte de los bultos correspondía a dinero por valor de tres millones de pesos y «no bajando de otro millón en que se llevaba en oro clandestinamente». Transcurridos varios meses, y tras vencer el acoso constante del millar de insurgentes que les acechaba, el convoy pudo llegar al puerto de Veracruz en abril de $1815^{5}$.

Sin duda la restauración constitucional en 1820 motivó que muchos españoles en México decidiesen retornar a su patria. José de la Lama se quejaba de que el comer-

\footnotetext{
1 GÁrate, 1989; 2000; Florencio, 2002; Solì.1985.

2 Fondo Francisco de Carranza (en adelante FFC). Debemos agradecer la gentileza del director de la página web Historias de Lanestosa, Manuel Ángel de la Cruz, quien nos facilitó el acceso y consulta de tan importante fondo inédito.

3 Alamán, 1942, pp. 146-148; LynCH, 2008, p. 320.

4 Carta de Félix Calleja al ministro de Gracia y Justicia. (Archivo General de Indias), Indiferente General, 110, México, 18-VIII-1814.

5 Alamán, 1942, pp. 158-163.
} 
cio ultramarino de Veracruz sufría en estas fechas un serio retroceso, que achacaba a un saturado mercado sin compradores, con escasez de numerario y al sentimiento generalizado entre los españoles de México de que "creyendo mala para la España la Constitución en ultramar; hay varios que recogen para retirarse a España"6.

Al declararse la independencia en 1821, los españoles europeos que decidieron marcharse pudieron hacerlo libremente, incluso llevando consigo sus caudales, en virtud de lo estipulado en el artículo 15 de los Tratados de Córdoba ${ }^{7}$. A pesar de ello, y de que el Plan de Iguala garantizaba la unión entre todos los habitantes de México, la animadversión contra los españoles aconsejaba la salida del país para proteger sus personas y bienes. El comerciante español en Veracruz Antonio Gómez logró embarcarse rumbo a España, tal y como decía el mismo: "yo concluí mis asuntos de la manera que pude y no como quería; empezando a sacrificar intereses pues de otra manera sería víctima como otros muchos perdiendo el todo para la parte"8.

Tal y como sucedió en el resto de territorios americanos, cuando lograron su independencia se produjo un importante movimiento migratorio compuesto fundamentalmente por funcionarios, militares, autoridades eclesiásticas y comerciantes fuertemente implicados con los intereses realistas. La incertidumbre de estos últimos ante los nuevos tiempos redujo de modo notable el flujo mercantil con la península, situación que se acentuó aún más a partir de la declaración de guerra del gobierno mexicano al español el 25 de febrero de 1823.

\section{VERACRUZ, PRINCIPAL PUERTO DE SALIDA DE CAUDALES DE MÉXICO}

Antes de adentrarnos en este asunto deberíamos señalar la enorme dificultad de discernir entre la plata enviada a Europa como moneda de pago o compra de mercancías, de la repatriada como consecuencia del abandono de la colonia por parte de los españoles que habían decidido no regresar a la que fuera su hogar durante años, aunque todos sabemos que debido a la escasez de las fuentes resulta casi una empresa imposible. Asimismo la ausencia de registros y las continuas incautaciones realistas e insurgentes hacen muy difícil conocer la cifra precisa de los caudales extraídos por particulares durante los últimos años de virreinato.

Para poder tener una idea más precisa de la importancia de la plata exportada es necesario que conozcamos, aunque sea de modo sucinto, el conjunto de exportaciones mexicanas entre los años 1821 y 1828. En este periodo de tiempo podemos observar dos grandes variaciones; por una parte un movimiento descendiente entre 1821 y 1823 y otro ascendente a partir de 1824 y hasta 1828 , con el momento de mayor expansión entre los años 1825 y 1827 . Los metales preciosos y minerales constituyen, en promedio, más del $70 \%$ de la exportación anual seguido de la grana cochinilla.

6 Carta de José de la Lama a Francisco de Carranza. Veracruz, 13-IX-1820. FFC.

7 Díaz - Martini, 1977. Art. 15 de los Tratados de Córdoba: “[...] que no podrá negárseles, para salir del reino en el tiempo que se prefije, llevando o trayendo consigo sus familias y bienes; pero satisfaciendo a la salida por los últimos, los derechos de exportación establecidos o que se establecieren por quien pueda hacerlo".

8 Carta de Antonio Gómez a Francisco de Carranza. La Habana, 14-IX-1821. FFC. 
Ocasionalmente destacan otros productos tales como la plata pasta-quintada, el oro acuñado, la vainilla, el palo de tinte y otros productos agrícolas. La plata labrada y en barras en 1821 y 1828 ocuparon el tercer producto de exportación, suponiendo entre el 3 y $7 \%$ de la exportación anual.

Tabla 1. Tipos de productos mexicanos de exportación y su valor en pesos.

\begin{tabular}{|l|r|r|r|r|r|r|r|}
\hline $\begin{array}{l}\text { Tipos de } \\
\text { productos }\end{array}$ & $\mathbf{1 8 2 1}$ & $\mathbf{1 8 2 3}$ & $\mathbf{1 8 2 4}$ & $\mathbf{1 8 2 5}$ & $\mathbf{1 8 2 6}$ & $\mathbf{1 8 2 7}$ & $\mathbf{1 8 2 8}$ \\
\hline $\begin{array}{l}\text { Metales y } \\
\text { minerales }\end{array}$ & 8.423 .966 & 1.324 .970 & 2.836 .132 & 3.704 .123 & 5.854 .160 & 9.670 .358 & 12.391 .467 \\
\hline $\begin{array}{l}\text { Tinturas } \\
\text { vegetales }\end{array}$ & 1.395 .053 & 923.867 & 1.568 .987 & 1.113 .166 & 1.504 .824 & 1.207 .508 & 1.812 .561 \\
\hline $\begin{array}{l}\text { Productos } \\
\text { agrícolas }\end{array}$ & 97.632 & 57.637 & 52.388 & 90.352 & 70.102 & 1.025 .209 & 114.056 \\
\hline $\begin{array}{l}\text { Productos } \\
\text { pecuarios }\end{array}$ & 19.279 & 11.395 & 2.744 & 107.402 & 109.784 & 159.323 & 34.348 \\
\hline $\begin{array}{l}\text { Medicinas } \\
\text { vegetales }\end{array}$ & 17.260 & 10.434 & 23.784 & 5.236 & 12.627 & 11.270 & 103.539 \\
\hline
\end{tabular}

Fuente: HERRERA, 1977, pp.58-59.

Las fábricas textiles francesas importaban de México las plantas tintóreas y la cochinilla o grana, que necesitaban para completar el proceso de teñido de los tejidos, alcanzando entre el 10 y el 39\% de las exportaciones anuales. De hecho, era común que en caso de no poder cobrar en plata se hiciera en grana, tal y como lo atestigua el repatriado español Antonio Gómez cuando pidió a su apoderado en Cádiz que "[...] si no es fácil vender mis efectos a plata, lo hagas a cambio de granas" ${ }^{\prime \prime}$. Los productos como la vainilla (90\%), la pimienta de Tabasco (4\%), y en menor grado el azúcar representaban entre el 1 y $2 \%$ del total de exportaciones mexicanas en esta década, observándose un repunte importante en 1827 cuando supuso el 8\% de la exportación total $^{10}$.

Respecto al volumen de plata extraída desde 1776 a 1824, Javier Ortiz de Tabla Ducasse nos indica que en 25 años (1766-1791) la corona y comerciantes sacaron de Veracruz alrededor de 128 millones de pesos, de los cuales casi el 90\% correspondía al tesoro real y solo el 10,38\% pertenecía a transacciones privadas. De 1796 a 1819 la extracción de plata aumentó hasta convertirse en el porcentaje de exportaciones más alto que salió de Veracruz. En 1816 la plata representó el 96,22\% del total de exportaciones y el $91,24 \%$ en $1818^{11}$. Según Jiménez Codinach, el agente de Reid \& Irving, Charles Parke, sacó plata de Veracruz por valor de 3 millones de pesos entre septiembre de 1815 y febrero de 1816 y, a finales de 1815, llegaron a Inglaterra casi 7 millones de pesos $^{12}$. El agente británico Henry Ward indicaba que con la separación

\footnotetext{
9 Carta Antonio Gómez a Francisco de Carranza. La Habana, 30-III-1822. FFC.

10 Herrera, 1977, pp. 58-59.

11 Ortiz De LaTabla, 1978, p. 154.

12 JiMÉNEZ, 1998, pp. 329, 335 y 346.
} 
de España, todo el excedente de capital que quedaba en México salió de la circulación $\mathrm{y}$, aunque no pudo certificar la cifra concreta porque la mayor parte se hizo en secreto, sus mejores informantes suponían que esta cantidad se podría situar entre 80 y 140 millones de pesos ${ }^{13}$. Esta fuga de caudales produjo una descapitalización directa de las finanzas mexicanas, en donde salía más plata de la que se producía ${ }^{14}$. Asimismo señalaba que la Casa de la Moneda de la ciudad de México acuñó 5,7 millones de pesos en monedas de oro y plata en 1822 , y que durante el mismo año al menos 7,3 millones de pesos salieron del país (5,4 millones se exportaron a España, 1,2 millones a los EE.UU. y 607.000 pesos a Europa $)^{15}$.

El agente inglés R. Staples escribía en junio de 1823 desde la ciudad de México cómo "la plata amonedada, que anteriormente estaba en circulación, estaba o bien oculta o bien sus propietarios buscan algún canal para transportar a Europa"16. El agente francés Alex Martin informó, en 1827, que en los últimos tres años "más de 40 millones de pesos, propiedad de españoles, salieron rumbo a Burdeos" ${ }^{17}$. Finalmente Sims, en base de los datos aportados por Carlos $\mathrm{M}^{\mathrm{a}}$ Bustamante, sostenía que en enero de 1829 los españoles se habían llevado 34 millones de pesos ${ }^{18}$. A su vez Robert Potash, basándose en los trabajos de R.H. Humphreys y de los informes consulares británicos, nos ofrece unas cifras muy poco concretas al sostener que el capital huido de México después de 1820 varió entre los 36,5 y los 140 millones de pesos ${ }^{19}$.

Hasta la ruptura de relaciones en octubre de 1823, la plata siguió saliendo con relativa normalidad, no exenta de obstáculos, hacia La Habana o Cádiz. El ministro mexicano de Hacienda, Rafael Pérez Maldonado, denunciaba ante el Congreso el 24 de mayo de 1822 "que sesenta millones de pesos en dinero y barras, llevados desde México, estaban depositados en La Habana"20.

Ante el temor de que fueran incautadas las mercancías y caudales por el nuevo régimen, los comerciantes españoles que guardaban en Veracruz valores y mercancías calculadas en unos veinte millones de pesos decidieron guardarlos en el castillo de San Juan de Ulúa, único reducto realista que resistía, con la intención de comerciar desde este enclave o bien llevarlos a la cercana isla de $\mathrm{Cuba}^{21}$. Mientras perduró el comercio con la península y Cuba remitieron los caudales en buques españoles hasta que se vieron obligados a embarcarlos en buques extranjeros o introducirlos furtivamente en el Castillo de San Juan de Ulúa, a cambio de "grandes riesgos y sacrificios de sus intereses por las manos intermedias de que tenían que valerse" 22 . Para finales

13 WARD, 1981, p. 451.

14 Sims, 1982, pp. 223 y 224. Este autor indica que a raíz de la extracción de capitales, la acuñación de monedas que hacia 1826 había descendido subió a más de diez millones de pesos en 1827-1828 y hasta doce en 1829. Sims dice taxativamente que "el estímulo era, claramente, la exportación de dinero en moneda por los peninsulares que provocó la escasez de circulante y bancarrota pública".

15 WARD, 1981, pp. 471-473; LADD, 1984, pp. 225-226, también es de la misma opinión que el observador inglés.

16 Public Record Office. Londres, F.O., 72, 275, nº 25, fol. 185.

17 Torre Villar, 1957, p. 59.

18 Sims, 1982, p. 56.

19 Humphreys, 1940, pp. 303 y ss.

20 Alamán, 1942, p. 587.

21 Guerra, 1998, pp. 32-45.

22 Franco, 1961, pp. LXXVIV-LXXIX. 
de 1823, la presencia de barcos de guerra españoles en México era inexistente por lo que todo envío de caudales se podía hacer de dos modos; bien en uno de los barcos mercantes con el elevado coste de $6 \frac{1}{2} \%$ en concepto de seguro y fletes (consecuencia del temor de que España y Francia se declararan la guerra) ${ }^{23}$, o bien como aconsejaba Carranza en barcos de guerra británicos con destino a Londres "consignándolo a D. Joaquín Ruiz de Alcedo, mi correspondiente allí para que lo tenga a mi disposición" 24 .

Finalmente el 23 de noviembre de 1825, la fortaleza de San Juan de Ulúa se rindió tras el acoso de la armada mexicana y del endurecimiento del asedio del ejército mexicano. Para estas fechas los comerciantes radicados en La Habana o sus consignatarios en Veracruz ya habían extraído sus bienes del castillo y enviados a Cuba y a Londres. Respecto a este asunto Carranza indicaba a su paisano Antonio Gómez que el dinero que tuviera en el castillo de San Juan de Ulúa debía aprovechar el primer buque de guerra inglés que allí se presentase para Londres, consignándoselo a Joaquín Ruiz de Alcedo o Pedro Casimir Timerman, "pues tanto plata, como granas no debe venir a la península, por los descomunales reglamentos" 25 .

Dionisio Gómez de Velasco, consignatario y encargado de remesar la plata de Antonio Gómez en Veracruz, le anuncia a este último que para sacar del castillo el dinero y hacer remesa tuvo que hacerse cargo del flete, derechos y gastos sobre Londres al $12 \%$ del metálico y librarlo sobre esa plaza "cargándose el premio de 9\%" 26 .

Tabla 2. Relación de embarcaciones que remesaron caudales desde Veracruz -vía La Habanadesde los meses previos a la declaración de independencia hasta finales de $1822^{27}$.

\begin{tabular}{|l|r|r|}
\hline \multicolumn{1}{|c|}{ BUQUE } & \multicolumn{1}{|c|}{$\begin{array}{c}\text { ARRIBO } \boldsymbol{A} \\
\text { CADIZ }\end{array}$} & \multicolumn{1}{c|}{ PESOS } \\
\hline El Constitución & $31 / 12 / 1820$ & 3.300 .000 \\
\hline Nueva Veloz Mariana & $/ 10 / 1821$ & 1.700 .000 \\
\hline Guadalupe & $26 / 12 / 1821$ & 30.000 \\
\hline Encantadora & $29 / 12 / 1821$ & 14.300 \\
\hline Ntra. Sra. del Carmen & $31 / 12 / 1821$ & 340.000 \\
\hline El Voluntario & $18 / 03 / 1822$ & 3.000 .000 \\
\hline Asia & $20 / 03 / 1822$ & 139.599 \\
\hline Diamante & $21 / 03 / 1822$ & 67.771 \\
\hline Diamante & $09 / 04 / 1822$ & 490.926 \\
\hline La Fama & $03 / 08 / 1822$ & \\
\hline
\end{tabular}

\footnotetext{
23 Carta de Antonio Gómez a Francisco de Carranza. Madrid, 21-X-1823. FFC.

24 Carta de Francisco de Carranza a Marcelino Batiz. Cádiz, 28-X-1823. FFC.

25 Carta de Francisco de Carranza a Antonio Gómez. Cádiz, 15-VI-1825. FFC.

26 Carta de Antonio Gómez a Francisco de Carranza. Madrid, 14-VII-1825. FFC.

27 Ruiz De Gordejuela, 2006, p. 84. Estos buques, incluidos los de guerra como la fragata Guadalupe y el navío Asia, zarparon de Veracruz después de declararse la independencia. El Asia salió del puerto mexicano el 11 de noviembre de 1821 con destino a La Habana, entrando en el Morro de este puerto el 9 de enero transportando en sus bodegas 2.300 .000 pesos y 700 sobornales de añil. Tras 52 días de navegación, el navío fondeó en el puerto de Cádiz el 20 de marzo de 1822, con una carga de 3 millones de pesos, tras cargar otros 700.000 pesos en La Habana. Archivo de la Marina, Viso del Marqués, Independencia de América, Expediciones a Indias, 4192.
} 


\begin{tabular}{|l|r|r|}
\hline Alerta & $09 / 08 / 1822$ & 24.000 \\
\hline L'Antigone & $13 / 09 / 1822$ & 1.700 .000 \\
\hline San José & $19 / 09 / 1822$ & 28.300 \\
\hline El Vengador & $06 / 11 / 1822$ & 207.527 \\
\hline
\end{tabular}

Fuente: Ruiz DE Gordejuela, 2006, p.84.

Lucas Alamán concretó en 30 millones los pesos que se trasladaron a Cuba entre 1821 y 1825 , dinero que sin duda repercutió muy favorablemente en la economía de la isla.

El Diario Mercantil de Cádiz publicaba el 12 de junio de 1827 que, según la información que había traído la fragata Tweed, la cantidad en barras de oro y plata exportada desde el puerto de Veracruz, entre principios de 1825 y 30 de enero de 1827 , ascendió a 5.260.100 pesos, y desde el de Tampico a 1.623 .337 pesos. Asimismo se embarcó grana desde el puerto jarocho por valor de 760.000 y añade el citado diario que el importe probable de las letras alcanzarían los 2.516 .563 pesos haciendo un total de 10.160.000 pesos. A su vez las remesas realizadas desde Veracruz por cuenta del comercio desde 20 de diciembre de 1825 hasta 30 de enero de 1827 ascendieron a los 349.108 pesos, mientras que por cuenta del gobierno esta cifra supuso los 1.238.000 pesos. A saber 283.000 en el Pyramus, 500.000 en el Hussar, 500.000 en el Tweed. En Tampico la exportación de oro y plata desde $1^{\circ}$ de enero hasta 30 de septiembre de 1826 ascendió a 1.070 .334 pesos. Hay que tener presente que estas cifras no contemplan toda la plata labrada y amonedada que salió de modo clandestino ${ }^{28}$.

Aunque las autoridades mexicanas eran de la opinión que los dineros españoles ya habían salido del país, tal y como sostenía la Memoria que presenta el Gobierno de Guanajuato al Congreso Constituyente del Estado de V 1824 a XII 182529, las dos leyes de expulsión de españoles en años siguientes vendrán a demostrar que todavía los españoles de México seguían guardando una importante cantidad de plata y oro.

No cabe duda que los impuestos sobre la exportación de plata eran una fuente vital para la nueva economía mexicana, por lo que desde un primer momento se establecieron importantes derechos sobre esta.

El gobierno de Iturbide aprobó el 15 de diciembre de 1822 un arancel por el que se cobraba por su salida marítima el $5 \%$ para la plata y el 3\% para el oro en pasta ${ }^{30}$.

28 Diario Mercantil de Cádiz, nº 3.968, 12 de junio de 1827.

29 Chávez, 1966.

30 Cruz, 2005, pp. 82 y 83. Este autor cita a otros colegas como Tenenbaum, 1998, pp. 216 y 217. 
Tabla 3. Derechos comparativos levantados sobre la plata en moneda y en barras en México, de acuerdo con las leyes existentes relativas a moneda (20 de febrero de 1822) y el Decreto del 19 de julio de 1822 que permite la exportación de barras ${ }^{31}$.

\begin{tabular}{|r|l|r|}
\hline \multicolumn{1}{|c|}{ BARRAS } & \multicolumn{1}{c|}{ DERECHOS } & \multicolumn{2}{|c|}{ MONEDA } \\
\hline $3 \%$ & Territorial & $3 \%$ \\
\hline $1 \frac{1}{2 \%} \%$ & Minería & $3 \%$ \\
\hline $7 \%$ & Moneda & $3 \frac{1}{2} \%$ \\
\hline $7 \%$ & Exportación & 11 \\
\hline $11 \frac{1}{2}$ & & $2 \%$ en depósito \\
\hline Propuesto $2 \%$ & Circulación & 13 \\
\hline $13 \frac{1}{2}$ & TOTAL & \\
\hline
\end{tabular}

Fuente: Grajales, 1969, p.77.

Esta medida se mantuvo hasta el 10 de mayo de 1826 cuando se decretó la libertad de derechos a la exportación de los géneros, frutos y efectos nacionales, no pudiendo ni los estados por donde transiten ni por sus costas imponer cobro alguno bajo ninguna denominación, a excepción de "oro acuñado, debiendo pagar un $2 \%$, oro labrado en piezas, debiendo pagar un $2 \%$ y plata acuñada y labrada, 3,5\%". El 16 de noviembre de 1827 se expidió un segundo arancel para las aduanas marítimas y de frontera de la República mexicana por el que "se prohibía asimismo la exportación de oro y plata en pasta, piedra y polvillo, monumentos y antigüedades mexicanas, así como la semilla de la cochinilla"32.

\section{LONDRES, PRINCIPAL DESTINO DE LA PLATA MEXICANA TRAS LA INDEPENDENCIA}

En 1818 el comerciante vizcaíno asentado en Veracruz, José de la Lama, informaba a su consignatario en Cádiz que ya no era "posible pasar ya dinero a bordo de los buques de guerra ingleses sin gran peligro de perderlo, con lo que se ha cortado este recurso"33. Meses más tarde el propio Lama pudo enviar una remesa a Londres de 2.000 pesos, ya que en palabras de Carranza "la venta de la plata en Londres anda equilibrada siempre con el cambio, corriendo un paralelo; aunque cueste algo más por razón de seguridad tiene cuenta por dicha vía" ${ }^{34}$. En cuanto los caudales se depositaban en la capital inglesa los consignatarios tomaban letras sobre esta plaza tal y como se venía haciendo con los retornos que se enviaban para evitar el corso ${ }^{35}$. Estos 2.000 pesos fuertes recibidos por la fragata de guerra de S.M.B. Harrier supusieron 468 libras, 10 chelines y 10 peniques (a 65 pesos por onza), a los que hubo

\footnotetext{
31 Grajales, 1969, p.77..

32 CRUZ, 2006, pp. 119-167.

33 Carta de José de la Lama a Francisco de Carranza. Veracruz, 28-V-1818. FFC.

34 Carta de Carranza a José de la Lama. Cádiz, 15-IX-1818. FFC.

35 Carta de Francisco Ortiz a Francisco de Carranza. Pánuco, 29-X-1818. FFC.
} 
que descontar $11 £, 14 \mathrm{~s}$. y $3 \mathrm{~d}$. de flete desde Veracruz (a $2 \frac{1}{2} \%$ ), $10 £$ y $6 \mathrm{~s}$. por peso y entrega de dos sacos, $11 £, 9 \mathrm{~s}$. de corretaje $(1,8 \%)$ y $4 £, 13 \mathrm{~s}$. y $9 \mathrm{~d}$. por el $1 \%$ de comisión que cobró su consignatario en Londres, la casa Tastet, Lacoste y $\&^{36}$, por lo que al Sr. Lama le depositaron $451 £$ y $7 \mathrm{~d}$. Posteriormente este capital, como otros cuyo destino era Cádiz, tuvo que pagar en concepto de garantía de la remesa el $1 \frac{1}{2} \%$ $(2 £, 4 \mathrm{~s}, 9 \mathrm{~d})$, corretaje $1 £ \%$ o $(8 £, 11 \mathrm{~s}$.) y de portes y franqueos de cartas... $14 \mathrm{~s}$ y $4 \mathrm{~d}$. Finalmente Francisco de Carranza, último destinatario de esta remesa, recibió en la capital gaditana $447 £, 12 \mathrm{~s}$ y $7 \mathrm{~d}^{37}$. Ruiz de Alcedo informaba que la salida de plata en Londres con destino a Cádiz estaba en el 15\%1/2\% (en 1818 era de $15 \%$ ) y un 2\%o por encajonado y conducción ${ }^{38}$.

El precio de la plata en Londres sufrió importantes variaciones dependiendo en gran manera de la cantidad de plata depositada en la capital británica. Al respecto, el citado Alcedo advertía que el Banco [en Londres] no estaba dispuesto a abonar más de $8653 / 8$ por cada 1.000 pesos $^{39}$.

Hacíamos referencia en páginas anteriores a la necesidad de intentar establecer qué cantidades de plata y oro eran consecuencia del intercambio comercial o de la fuga de capitales en búsqueda de un destino más seguro. Pues bien, asimismo, debemos intentar desenmarañar otro factor importante, nos referimos a que si la plata que era enviada al exterior correspondía al pago de los intereses producidos por los préstamos concedidos en Inglaterra a los gobiernos mexicanos. El estudio de la numerosa correspondencia particular entre comerciantes de ambas orillas nos ha permitido obtener una importante conclusión, y es que la mayor parte de las pretendidas remesas inglesas para hacer frente el pago de los dividendos de los empréstitos mexicanos en realidad tenía como destinatario a comerciantes o consignatarios particulares. El embajador español en Londres, conde de Ofalia, escribía a Madrid que el buque Phylades procedente de Veracruz, en vez de transportar los fondos para el pago de los dividendos, "no traía ni una peseta para este objeto, y sí solo 900.000 pesos para particulares, que la mayor parte se suponen ser fondos de españoles que emigran" 40 .

Tabla 4. Relación de barcos de S.M.B. que trasladaron caudales de México a Inglaterra entre los años 1820 y $1830^{41}$.

\begin{tabular}{|l|r|r|r|r|}
\hline BARCO & CAPITÁN & PUERTO & FECHA & VALORES Y ESPECIES \\
\hline Jyne & & Veracruz & $/ 10 / 1820$ & \\
\hline Nancy & Dowling & San Blas & $/ 07 / 1821$ & $500.000 \$$ \\
\hline Conway & & San Blas & $/ / 1822$ & \\
\hline
\end{tabular}

36 Al menos desde 1813, la casa comercial era conocida por Tastet, Lacoste y Sartoris. El 31 de diciembre de 1818, justo después de hacer esta venta, la casa cambia de nombre al retirarse a España Juan Lacoste, cambiando esta por el de Tastet, Burgué y Cía., dirigida por Fermín Tastet y su sobrino Alejandro Burgué.

37 Carta de Tastet y Lacoste y \&. a Fco. de Carranza. Londres, 9-XII-1818. FFC.

38 Carta de Francisco Fernández de la Colina a Francisco de Carranza. Madrid, 25-V-1819. FFC.

39 Carta de Francisco de Carranza a José Joaquín Ruiz de Alcedo. Cádiz, 7-XI-1820. FFC.

40 Carta del embajador en Londres conde de Ofalia al ministro Manuel González Salmón. AGI, Estado, $42, \mathrm{n}^{\circ} 74$, doc. $\mathrm{n}^{\mathrm{o}} 292$, Londres, 12-II-1828.

41 Información obtenida del trabajo de la Dra. Grajales y de aportaciones propias. 


\begin{tabular}{|l|r|r|r|r|}
\hline Aurora & & San Blas & $16 / 02 / 1824$ & \\
\hline Tartar & & San Blas & $/ 03 / 1826$ & $1.500 .000 \$$ \\
\hline Hussar & Harris & Veracruz & $20 / 08 / 1826$ & $2.000 .000 \$$ \\
\hline Alacrity & & San Blas & $/ / 1826$ & \\
\hline Jaseur & & San Blas & $29 / 04 / 1827$ & $1.500 .000 \$$ \\
\hline Blossom & Beechey & San Blas & $12 / 10 / 1827$ & Pago de dividendos préstamo \\
\hline Phylades & Jackson & Veracruz & $15 / 10 / 1827$ & $500.000 \$$ \\
\hline Tweed & Hunn & Veracruz & $25 / 12 / 1827$ & Pago de dividendos, 500.000 \$ \\
\hline Valorous & Hutingdon & Veracruz & $15 / 12 / 1827$ & \$(de españoles) \\
\hline Phylades & & Veracruz & $10 / 02 / 1828$ & Pago de dividendos 900.000 \\
\hline Seylla & Hobson & Veracruz & $10 / 02 / 1828$ & \\
\hline Blossom & Beechey & San Blas & $24 / 03 / 1828$ & 600.000 \$ y 82 cajas de plata \\
\hline Rinaldo & & Veracruz & $04 / 08 / 1828$ & \\
\hline Aurora & & Veracruz & $21 / 08 / 1828$ & \\
\hline Blossom & & San Blas & $14 / 10 / 1828$ & \\
\hline Druid & & Veracruz & $23 / 02 / 1829$ & \\
\hline Alert & & San Blas & $19 / 03 / 1829$ & \\
\hline Queensbury & & Veracruz & $11 / 03 / 1829$ & propiedad mayoritaria de ingleses a \\
Inglaterra
\end{tabular}

Fuente: Grajales, 1969, p.77 y ss.

\subsection{San Blas, puerto de salida de los caudales de la costa oeste mexicana y su traslado a Londres}

A pesar de que en 1779 el visitador del Perú, Antonio de Areche, apostó por la apertura comercial entre los puertos peruanos y San Blas, esta no se llevó a cabo en esos momentos al estar inhabilitado para comerciar y porque esta iniciativa se encontró de frente con los intereses del todopoderoso Consulado de comerciantes de México. Finalmente en 1796 se le otorgaron los permisos para comerciar con las plazas de Guayaquil, El Callao, Realejo y Sonsonate, lo que le permitió introducir legalmente mercancías procedentes de puertos hispanoamericanos y fortalecer sus relaciones con el gremio de comerciantes de Guadalajara. Estos últimos defendieron las relaciones comerciales con panameños y peruanos que facilitasen la entrada de efectos extranjeros y la salida de plata por el puerto de San Blas y otros puertos del noroeste, como el de Guaymas ${ }^{42}$.

La toma de Acapulco por las tropas de Morelos entre 1810 y 1813 convirtió a San Blas en el puerto más importante del Pacífico mexicano. La práctica imposibilidad de ejercer el comercio entre el noroeste novohispano con la ciudad de México y Vera-

42 PinZÓn, 2008, pp. 159-160. 
cruz sin ser asaltado por las fuerzas insurgentes obligó al general de la Cruz, comandante en jefe de la región, a que se permitiera la introducción de mercancías por San Blas y la libertad de extraer de caudales, a cambio del cobro del $4 \frac{1}{2} \%$, por derechos de importación y del 10\% sobre las extracciones de metálico. Tan pronto esta medida llegó a los oídos del virrey Calleja fue suspendida ya que, a diferencia de lo que ocurría en el resto del virreinato, se permitía extraer la plata en pasta sin ningún cobro ${ }^{43}$.

Lo cierto es que sacar capitales amonedados por la costa oeste en este periodo resultó muy costoso, pagándose hasta el $13 \%$ en impuestos, tal y como lo refleja una carta del comerciante Francisco Ortiz a su primo, el citado Carranza, en la que le indica que "esta es la causa de que muchos no manden dinero y aún a que los hombres acaudalados teman el transportarse a España" ${ }^{44}$.

El comercio con Panamá no se restringió solo a la Nueva Galicia, sino que se extendió al golfo californiano, de ahí que el subdelegado de Real Hacienda y administrador de alcabalas del Real de Minas del Rosario, solicitara se reconociera al puerto de Mazatlán con los mismos privilegios que San Blas para poder comerciar en igualdad de oportunidades que sus colegas de Tepic ${ }^{45}$.

En 1818 cuando el comercio con Panamá empezó a declinar, el Consejo de Indias permitió que este comercio pudiera hacerse con los recién habilitados puertos de Punta Arenas (Nicaragua) y Guaymas en Sonora y que sus pagos se realizaran en oro y plata amonedados libres de derechos ${ }^{46}$.

Tal y como comentábamos, las enormes dificultades que suponía enviar las mercancías desde la costa oeste hasta el puerto de Veracruz incentivó a las autoridades españolas de la Nueva Galicia a considerar la opción de utilizar sus puertos como centro de intercambios comerciales entre ingleses y novohispanos.

El antecedente más cercano de envío de caudales en un barco de la Marina Real Británica desde la costa oeste americana es de diciembre de 1817, cuando la fragata Anfión transportó 200.000 pesos procedentes del Callao y Valparaíso con destino a Londres, propiedad de, tan solo, comerciantes ingleses al negarse el comodoro Bowles, a recibir dineros que no fueran de su nacionalidad; actitud imitada por el capitán Shirreff, de la Andrómaca, en mayo 1818. Ante esta circunstancia, algunos comerciantes locales decidieron designar agentes británicos para que se hicieran cargo de sus transacciones comerciales con el objeto de conseguir colocar su plata en Londres. Los dos primeros españoles en hacerlo fueron Licarazo y Murrieta, cuando en octubre de 1819 embarcaron 348.000 pesos en el Slaney y unos meses más tarde, en mayo de 1820, el ejemplo fué seguido por el comerciante limeño Manuel Ortiz de Villalta, quien cargó en el Tyne 844 cajas de especias y 3.008 .513 pesos $^{47}$. Aunque desconocemos la identidad de los consignatarios de estos envíos sabemos que cuando

43 Trejo, 2014, p. 119.

44 Carta de Francisco Ortiz a Francisco de Carranza. Pánuco, 9-X-1818. FFC.

45 Román, 1998, pp. 17-18. Su apertura al comercio internacional aunque fue decretada por las cortes españolas en 1820 solo se logra hasta el 6 de febrero de 1822, pese a que durante la Insurgencia el gobernador de la Intendencia de Sonora, para evitar el contrabando de este puerto, permitió el intercambio de mercancías entre mineros y comerciantes ingleses y norteamericanos.

46 Ibídem, p. 121.

47 Ortiz-Sotelo, 1998, p. 603. 
el Hyperion partió en diciembre de 1820 del Callao con más de 1.500 .000 pesos propiedad de los locales comerciantes, Larraza y Mocrai, su representante en la capital británica era el comerciante Anthony Gibbs ${ }^{48}$.

Para el historiador W.A. Mathew los comandantes británicos anteponían su propio interés comercial por encima de sus deberes, opinión que no es compartida por el más destacado especialista en este tema, Barry M. Gough, quien considera que el servicio naval en la costa oeste de México jugó un papel destacado al brindar seguridad a los comerciantes durante los precarios tiempos de la revolución y emergencia nacional en Latinoamérica. Pronto los comerciantes británicos en el Pacífico español comprendieron que el modo más operativo de enviar dinero a Inglaterra era utilizando los barcos de su Majestad Británica, cuyos seguros y fletes era menores que los cobrados por las embarcaciones mercantes. En julio de 1819 el rey Jorge III fijo una tasa al respecto variando en función del punto desde donde se hiciera dicho embarque. De este modo, se pagaba de "Inglaterra a más allá de los cabos de Hornos y de Buena Esperanza, 1\% sobre los fondos públicos en tiempo de guerra o de paz, 2,5\% sobre los fondos privados en tiempos de paz y $3 \%$ en tiempos de guerra". Asimismo, ordenaba el rey inglés, en concepto de adehalas, que una cuarta parte de lo obtenido por las tarifas fuera asignada al almirante jefe de la estación, la mitad al comandante del buque y otra cuarta parte al Hospital de Marineros de Greenwich ${ }^{49}$.

La primera noticia de que disponemos del transporte de caudales procedentes de San Blas en barcos ingleses nos la ofrece Ortiz-Sotelo al indicar que el mercante Nancy cargó mercancías y plata de este puerto realista en 1821 rumbo al Callao y que fue interceptado por la fragata de guerra británica Consecuencia, quien confiscó toda su carga al comprobar que procedía de un puerto español ${ }^{50}$.

Pero, detrás de esta actitud protectora de los intereses comerciales británicos y de las comisiones que obtenían los oficiales de la escuadra del Pacífico, también se encontraba el lucrativo negocio de la acuñación de pesos de plata, por el que se obtenía en este proceso casi el $11,5 \%$ de su valor.

Ortiz-Sotelo ya nos advierte que un número considerable de comerciantes trataban de evitar una alta tributación mediante el pago de sobornos a las autoridades locales ${ }^{51}$.

De la misma opinión es Barry M. Gough, quien nos muestra las circunstancias y dificultades que encontró la fragata Blossom, a cuyo mando se encontraba el capitán Frederick William Beechey, cuando en derrota de la expedición al Paso del Noroeste visitó el puerto de San Blas el 20 de diciembre de 1827. Beechey, a solicitud del vicecónsul británico en Tepic, Eustace Barron, retrasó su partida durante más de tres meses para dar tiempo a los comerciantes de la región a que pudieran trasladar hasta este puerto sus caudales (extendiendo su radio de acción al Golfo de Californias). Barron sugirió que el barco de guerra que se destinara a estas costas tocase tierra en primer lugar en Acapulco para que a su llegada se diera a conocer este hecho en la capital de México y de este modo sus poderosos comerciantes informaran a sus agentes de los

\footnotetext{
48 Ibídem, p. 606.

49 Cit. Ortiz-Sotelo, 2005, pp. 211-213.

50 Ibídem, pp. 97 y 98.

51 Ibídem, p. 234.
} 
puertos del Pacífico ${ }^{52}$. El primer teniente del Blossom, George Peard, se quejaba en su diario de que las tasas para la exportación de metales preciosos eran tan:

extremadamente opresivas que incluso los comerciantes más respetables no tienen escrúpulos en evadir por completo o rebajar en cierto grado mediante el soborno a los funcionarios designados para recogerlos ${ }^{53}$.

La exportación ilegal supuso un volumen muy importante de los caudales enviados a Inglaterra por medio de su Armada. Gracias a un documento aportado por la Dra. Grajales podemos comprobar las tensas relaciones que mantenían las autoridades aduaneras mexicanas en San Blas con el vicecónsul de Inglaterra en ese puerto, Eustaquio Barron, por negarse este último a aceptar que un oficial de la aduana presenciara el embarque de caudales a bordo de un barco de guerra británico ${ }^{54}$.

Peard señaló que la plata o plata piña fue almacenada en barras, y que para la fundición del metal en barras el gobierno recibió el 5\%. Si las barras fueron convertidas en moneda, la cuota sería un 5\% adicional. La única forma en que la plata podría ser enviada legalmente fuera del país era pagando un $3 \frac{1}{2} \%$ más ${ }^{55}$.

Una valoración del total de plata exportada de la costa oeste de la América española en buques de guerra ingleses nos la ofrece el cónsul general británico en Lima, Charles Milner Rickets, quien cifraba esta cantidad, para el período 1819-1825, en 26,9 millones de pesos; mientras que su paisano John Stoddard Jones calculaba que esta ascendió a 22.295.000 pesos durante el periodo comprendido entre 1822 y $1825^{56}$.

A pesar de las enormes distancias y del hecho que enviar alguna nave de guerra a las costas mexicanas suponía un gran esfuerzo para la escuadra británica en el Pacífico, la urgencia de sacar importantes cantidades de plata, propiedad en la mayor parte de las ocasiones de los españoles que aún permanecían en la nueva República mexicana, y la oportunidad de que el gobierno mexicano pudiera hacer cualquier envío de dinero a Inglaterra como adelanto por los intereses de la deuda contraída en Londres, obligó a que entre los años 1822 y 1827 atracasen en esas aguas las fragatas Conway (1822), Aurora (1824), Alacrity (1826), Tartar (1826), Blossom (1827 y 1828), Jaseur (1827), Alert (1829) y Sapphire (1830).

Finalmente, en 1829 el contraalmirante Baker dispuso que un buque de guerra navegase hasta San Blas todos los meses de noviembre cada año, aunque, con el trascurso del tiempo, el transporte de caudales en barcos de guerra británicos fue perdiendo importancia a favor de los barcos mercantes artillados que se ofrecían con fletes y seguros más baratos ${ }^{57}$.

52 Public Record Office (Londres), Doc. 2567, ff. 285-286. Oficio, copia. Consulado de S.M.B. en San Blas, 18-III-1829.

53 Gough, 1983, p. 422.

54 Public Record Office, Doc. 2948, ff. 289-375. San Blas, 14-X-1829.

55 IPublic Record Office, Doc. 1219, ff. 47-1. Oficio nº 6, 2 anexo. México, 12-I-1828. Richard Pakenham al vizconde Dudley.

56 ORTIZ-SOTELO, 1998, p. 13.

57 Grajales, 1969 y Ortiz-Sotelo, 2005. 


\subsection{Los capitales refugiados en Londres y la quiebra de 1825}

Tras finalizar las guerras napoleónicas, Inglaterra y Francia se lanzaron a extender sus mercados por todo el mundo. Así, en los años previos a la quiebra de la "city" de Londres de 1825 se crearon 46 empresas que invirtieron en infraestructuras, actividades empresariales (especialmente minería) y déficits públicos en Hispanoamérica por valor de millones de libras (casi la mitad de los capitales arriesgados por el conjunto de las sociedades anónimas) que provocaron un boom en la Bolsa de Londres, por lo que el Banco de Inglaterra se vio obligado a subir el tipo de interés para preservar sus reservas de oro. Esta medida estranguló el flujo de dinero, colapsó la Bolsa y provocó impagos de deudas, pánicos bancarios y crisis monetarias en todas las nuevas repúblicas americanas.

Bárbara Tenenbaum sostiene que las numerosas casas comerciales que se declararon en quiebra (Goldschmidt and Company, Barcaly, Herring, Richardson and Company) determinaron que México perdiera 1.517.644 pesos que había depositado en estas. Los mercados de México ya estaban por completo saturados de mercancías inglesas y por consiguiente el comercio decayó inevitablemente en $1828^{58}$.

Finalmente los préstamos públicos en Inglaterra de 1824 y 1825 no se volvieron a repetir una vez que el gobierno mexicano cesara de pagar los dividendos en $1827^{59}$.

Un hecho desconocido es que una gran parte de los capitales repatriados de América por particulares se vieron involucrados en la quiebra londinense. Años antes, durante la primera década del siglo, consignatarios como Larrazábal, Menoyo y Troitaga ya recibían los caudales de los comerciantes de México y Perú que transportaban los barcos ingleses fruto de las transacciones mercantiles. Durante los años 1820 y 1825 sería el comerciante vizcaíno asentado en Londres Joaquín Ruiz de Alcedo quien recibiría gran parte de las remesas de plata y oro que los españoles de América enviaron a dicha plaza. Posteriormente, los comerciantes Aguirresolarte, Murrieta, Lizaur, Mariategui, Tastet y Zulueta ocuparán el espacio dejado por Ruiz de Alcedo.

La noticia de la quiebra en 1825 de la casa de Ruiz de Alcedo en Londres supuso una gran sorpresa entre los comerciantes ultramarinos españoles. En palabras de José Joaquín de Aguirre este hecho causó:

Una derrota completa, en particular de americanos españoles emigrados del Perú y Nueva España [...] que abusando de los cuantiosos intereses puestos a su confianza por los emigrados de América, se han metido en negociaciones y empréstitos ruinosos ${ }^{60}$.

Para los comerciantes coetáneos, la quiebra de Ruiz de Alcedo fue consecuencia de una anterior, la de la casa comercial inglesa Samuel Williams ${ }^{61}$. Juan Abajas hablaba de más de $470.000 £$ de capital afectado, según le había informado la casa Aguirresolarte (nombrado síndico de la quiebra) \& Murrieta, de los cuales $460.000 £$ pertenecían a acreedores españoles y sus efectos pronto se hicieron notar en el des-

\footnotetext{
58 Tenenbaum, 1985, p. 46.

59 Platt, 1982, p. 257.

60 Carta de José Joaquín de Aguirre a Francisco de Carranza. Lisboa, 9-XII-1825. FFC.

61 Carta de José Joaquín de Aguirre a Francisco de Carranza. Lisboa, 14-XII-1825. FFC.
} 
censo de los fondos en París y Londres ${ }^{62}$. Para Francisco de Carranza unas quiebras desencadenaron otras desde el 23 de octubre de 1825, cuando afectó al primer eslabón de la cadena, la casa Samuel Williams, quien arrastró a la de Tomás Williams y Cía. de Gibraltar y a la de Andrés Vilches de Málaga. El comerciante Juan de Abajas fue informado por Aguirresolarte, síndico de esta quiebra, que repatriados españoles tales como a "Jáuregui le agarraron lo poco o mucho que tenía, a Sanjurjo que está en Galicia 25.000 duros, a los Quiroses 20.000, a Albéniz la mayor parte de su caudal, a Barreda 30.000" ${ }^{63}$. Asimismo, Abajas no duda en asegurar que los culpables de esta quiebra fueron las especulaciones y empréstitos indiscretos que "con hacienda ajena hicieron los extranjeros en fines del año pasado [1824] y principios del presente; y que se estaba viendo venir a cualquiera menos entendedor" ${ }^{\prime 64}$.

Para Juan José de Aguirre esto no hubiera sucedido si en España se hubiera dado:

una entera confianza pública para que los capitales que se han ausentado de España a correr riesgos confiados a manos extranjeras para que produzcan un mezquino interés, volviesen a fomentar el comercio interior y la agricultura ${ }^{65}$.

Pronto la plaza de Londres comenzó a recuperarse de esta ola de quiebras que hizo temblar la economía británica, y para principios del año siguiente los bancos que habían suspendido sus pagos comenzaron a trabajar, produciéndose un importante aumento en la acuñación de moneda procedente del extranjero ${ }^{66}$.

\section{LLEGADA DE CAUDALES A ESPAÑA}

El profesor Trujillo Bolio nos aporta en su publicación El péndulo mercantil una valiosa relación de embarcaciones y sus caudales procedentes de México que desembarcaron en el puerto de Cádiz procedente de un conjunto de fuentes muy diversas ${ }^{67}$.

Además de lo dicho por este investigador, el Diario Mercantil de Cádiz nos facilita información relevante respecto a la plata que legalmente entró en este puerto durante los años 1819 a 1822 procedente de los territorios españoles de América. Así, de 1819 , tan solo tenemos datos del total de pesos fuertes, que ascendió a 3.447.029 ${ }^{68}$. En ese momento, en concepto de derechos de flete y contado que paga la plata en Cá-

\footnotetext{
62 Carta de Juan de Abajas a Francisco de Carranza. Burdeos, 28-XII-1825. FFC.

63 Ibídem.

64 Carta de Francisco de Carranza a José Joaquín de Aguirre. Cádiz, 16-XII-1825. FFC.

65 Carta de José Joaquín de Aguirre a Francisco de Carranza. Lisboa, 21-XII-825. FFC.

66 Carta de José Joaquín de Aguirre a Francisco de Carranza. Lisboa, 3-XII-1825. FFC.

67 Trujillo, 2009. Fuentes utilizadas por este autor: Guía de Vigía de Cádiz. AGI, Indiferente General; AGN, Fondos Marina y Movimiento Marítimo; Gazeta de México; Jornal Económico y Mercantil de Veracruz; Correo Semanario Político y Mercantil de México.

68 Diario Mercantil de Cádiz, no 1.627 de 19 de enero de 1821, "Resumen del oro y plata que ha entrado en este puerto en todo el año próximo pasado de 1820 "; $\mathrm{n}^{\circ} 2.006$ de 1 de febrero de 1822 , "Resumen del oro y plata que procedentes de América ha entrado en este puerto en todo el año próximo pasado de $1821^{\text {"; }} \mathrm{n}^{\circ}$ 2.368 "Resumen del oro y plata que procedentes de América ha entrado en este puerto en todo el año pasado de 1822". Trujillo, 2009, p.107. En 1817 y a pesar de la decadencia de la amonedación de plata se envió a la península la suma de 1.782.446 pesos. Lejos están los 4.500 .000 pesos que se remesaron en 1809. Este autor
} 
diz procedente de la América española es del 13\% y “arriesgándolo en buque español cuesta el seguro el 12\% si llega, y si se pierde, un 50\%"69.

Tabla 5. Plata desembarcada en el puerto de Cádiz durante los años 1819 a 1822 procedente de los territorios españoles de América. (Diario Mercantil de Cádiz, 1819-1822).

\begin{tabular}{|c|c|c|c|c|c|}
\hline 1820 & $\begin{array}{l}P L A T A A C U- \\
\tilde{N} A D A \text { (pesos) }\end{array}$ & $\begin{array}{c}\text { ORO } \\
\begin{array}{c}A C U \tilde{N} A D O \\
\text { (pesos) }\end{array}\end{array}$ & 1821 & $\begin{array}{l}P L A T A A C U- \\
\tilde{N} A D A \text { (pesos) }\end{array}$ & $\begin{array}{c}\text { PLATA EN } \\
\text { BARRAS Y } \\
\text { LABRADA } \\
\text { (pesos) }\end{array}$ \\
\hline Guayaquil & 21.596 & & San Blas & 721.641 & \\
\hline Lima & 520 & & Honduras & 33.169 & \\
\hline Veracruz & 5.173 .276 & & Omoa & 6.000 & \\
\hline La Habana & 8.400 & 14.000 & Veracruz & 5.027 .442 & 62.335 \\
\hline \multirow[t]{2}{*}{ TOTAL } & 5.217 .792 & & La Habana & 579.323 & \\
\hline & & & TOTAL & 6.429 .911 & \\
\hline & 1822 & \multicolumn{2}{|c|}{$\begin{array}{c}P L A T A A C U \tilde{N} A D A \\
\text { (pesos) }\end{array}$} & $\begin{array}{c}\text { ORO ACUÑ } A D O \\
\text { (pesos) }\end{array}$ & \\
\hline & Guayaquil & & 200 & & \\
\hline & Lima & & 21.121 & 1.600 & \\
\hline & Omoa & & 8.912 & & \\
\hline & Veracruz & & 9.293 .356 & 175.93 & \\
\hline & La Habana & & 1.626 .549 & 543.319 & \\
\hline & TOTAL & & 11.670 .993 & & \\
\hline
\end{tabular}

Fuente: elaboración propia basada en El diario Mercantil de Cádiz, 1819-1822.

Esta información nos permite cotejarla con la aportada por el Diario Mercantil de Cádiz para el año 1819 y observamos que, o bien que las fuentes no son exactas, o que gran parte de los caudales que salieron de Veracruz quedaron depositados en La Habana. Desde este último puerto hasta la península se pagaba en 1820 en concepto de derechos de entrada un $12 \%$, un 6 o $8 \%$ de seguro, más un $1 \%$ de comisión en la capital cubana ${ }^{70}$.

En 1825 quedaba regulado que toda la plata u oro que se condujese de las posesiones españolas en América en embarcaciones extranjeras debía pagar el 4\% de habilitación de bandera, mientras que si esta procedía de puertos extranjeros y bajo pabellón extranjero estaría libre de todos derechos ${ }^{71}$. El citado comerciante y juez del comercio gaditano, José Joaquín de Aguirre, advertía que esta medida retraería la llegada directa de dichos metales, y "puesto que son libres conduciéndolos de puertos extranjeros, acudirán a ellos bajo doble expectativa, la de enajenarlos si

se basa en los datos aportados por Smith, 1947. (Plata salida de Nueva España.1805-1823), 1816 (6.514.724 pesos), 1817 (6.397.960), 1818 (3.803.437) y 1819 (6.013.911).

69 Carta de Francisco Ortiz a Francisco de Carranza. Pánuco, 29-X-1818. FFC.

70 Carta de Francisco de Carranza a Ignacio Pérez de Soto. Cádiz, 3-XI-1820. FFC.

71 Carta de José Joaquín de Aguirre a Francisco de Carranza. Lisboa, 4-XI-1825. FFC. 
el mercado ofrece cuenta o de transportarlos a España para dispensarse de dicho $4 \% " 72$.

Años más tarde, en 1831, Carranza escribiría a su sobrino Juan de Abajas comunicándole que la plata a su entrada en España pagaba en ese año un $13 \%$, al que había que agregar otros gastos menores y el seguro, alcanzando finalmente el 191/2 $\%{ }^{73}$.

Un aspecto que hemos observado es que las fuentes utilizadas por distintos investigadores señalan que los buques de la armada tenían tan solo como consignatario a Su Majestad el rey de España, pero la documentación particular de comerciantes implicados en la remesa de capitales nos demuestra que en realidad gran parte de estos envíos eran de particulares a particulares. Para determinar la cifra precisa de pesos y sus consignatarios sería preciso obtener los sobordos de cada embarcación, hecho harto difícil.

Según la plata era desembarcada, los consignatarios se encargaban de cumplir fielmente las instrucciones al depositarla en sus cuentas o, como era lo más habitual, enviar los caudales a las casas de amonedación de Sevilla y Madrid, en donde pagaban por la conducción $1 \frac{1}{2} \%$ en la plata y $1 / 4 \%$ en el oro ${ }^{74}$. La conducción más importante se produjo el 11 de julio de 1822 cuando se transportaron desde la capital hispalense a Madrid más de un millón de pesos, cantidad tan grande que provocó la bajada del cambio en la Villa y Corte.

El gobierno liberal aprobó el decreto de 16 de julio de 1822, por el que se respetaría a los emigrados y sus propiedades procedentes de las colonias de ultramar que deseasen regresar a España. En el trasfondo de esta medida se trasluce una clara inquietud por atraer hacia la península los cuantiosos capitales que salían de tierras americanas y que eran vitales para poder equilibrar la maltrecha balanza de pagos española. Finalmente, el congreso constitucional español declaró que desde $1^{\circ}$ de enero de 1821 quedase libre de derechos la plata y oro que llegara de América a la península, anulando el $9 \frac{1}{2} \%$ que se cobraba hasta esa fecha ${ }^{75}$. La vuelta al absolutismo en 1823 también trajo consigo cambios en la política monetaria y aduanera que afectó directamente a la cada vez más escasa llegada de caudales de la América española. De este modo el oro y la plata tendrían "el quebranto de de $4 \frac{1}{3}$ a $4 \frac{1}{2}$ en razón a la ley suprema de 24 quilates en lo primero y de 12 dineros en lo segundo que lo pusieron las cortes y en el día es el de 22 qq. y 11 dineros" ${ }^{\prime 7}$.

El Diario Mercantil de Cádiz de 28 de septiembre de 1824 anunciaba que tras el periodo revolucionario el gobierno modificaba los aranceles mercantiles. El oro y plata en moneda, pasta, polvo y en alhajas despedazadas quedaron libres totalmente de derechos y arbitrios a su entrada en la Península, mientras que el oro labrado en vajilla y en alhajas, con piedras o sin ellas debía pagar $1 / 2$ por ciento por estimación y la plata trabajada de cualquiera clase y forma pagase por el mismo concepto el $1 \%$.

72 Carta de José Joaquín de Aguirre a Francisco de Carranza. Lisboa, 25-XI-1825. FFC.

73 Carta de Francisco de Carranza a Juan de Abajas. Cádiz, 1-VII-1831. FFC.

74 Carta de Francisco de Carranza a Marcelino de Batiz. Cádiz, 30-VIII-1822. FFC.

75 Francisco de Carranza a José de la Lama. Cádiz, 23-XI-1820. FFC.

76 Carta de Francisco de Carranza a Francisco Ortiz. Cádiz, 16-XII-1823. En 1823 la Casa de Moneda de Sevilla pagaba el marco de oro de 24 quilates a 3.070 reales. FFC. 
Pero lo cierto era que para 1823 la llegada de caudales a España procedentes de la América continental y específicamente de México prácticamente había desaparecido. La plata, oro y ricas mercancías que salían de los puertos mexicanos terminaban desembarcando en los muelles de La Habana, Nueva Orleans, Londres y en el bastión de San Juan de Ulúa que resistía el acoso de las cañoneras mexicanas.

Para los capitalistas emigrados asentados en Londres, la falta de estabilidad política en España y de crédito internacional por la quiebra financiera de un estado español incapaz de cumplir sus compromisos prestatarios, impedía que los capitales recabasen en la península.

Respecto al volumen de plata mexicana de origen español depositada en Londres, D. C. M. Platt afirma que: "Desde una época muy temprana los Lizardi de Londres y México manejaban una considerable suma de capital fugitivo invertido, a cuenta de mexicanos y extranjeros residentes, en acciones públicas británicas y francesas" ${ }^{\prime 7}$. El conde de Ofalia, embajador de España en la capital del Támesis, estimaba que los capitales de estos repatriados en Francia e Inglaterra ascendían a más de 25 millones de pesos y comprendía la negativa de estos a regresar a la península, máxime cuando:

los capitalistas mismos de Cádiz, Barcelona y otros puntos de España, se han dado igualmente prisa, por las mismas causas, a echar sus capitales fuera del Reino e imponerlos en los fondos de Francia e Inglaterra ${ }^{78}$.

Este criterio también era compartido por un agente financiero enviado a España por la casa Rothschild a finales de 1823, cuando comunicaba a sus superiores que "los comerciantes y personas ricas estaban extrayendo sus capitales [de España]"79.

Si todas estas circunstancias no fueran suficientes para menoscabar el flujo de emigrantes y dineros a España, al menos desde 1825 la Junta Superior de Sanidad de Cádiz instó a que se cumplieran las precauciones sanitarias como medida de prevención contra la posibilidad de que un barco foráneo introdujese la fiebre amarilla. De este modo, desde el $1^{\circ}$ de junio a mediados de noviembre no serían admitidas en este puerto las embarcaciones procedentes del "Seno-mexicano, Antillas, Costa Firme, Nueva York, Filadelfia, Baltimore y demás puntos de la Carolina del Sur", o de cualquier otro lugar en el que se hubiera manifestado la enfermedad. Si así fuera, debería dirigirse al lazareto de Mahón o al de "las islas Bayonas de Vigo" para obtener el certificado de purificación, y si en la travesía no se hubiera presentado ningún caso la embarcación podría "dirigirse al primer punto si los dueños calculasen convenir así a sus intereses" $"$.

También hay que tener en cuenta la plaza de Gibraltar, en cuanto supuso un destino importante de la llegada de mercancías, plata y personas procedentes de las nuevas repúblicas americanas. Sin duda gracias al contrabando desde este puerto se introdujo gran cantidad de plata en España que sería necesario investigar para poder cuantificar.

77 Platt, 1982, p. 227.

78 Public Record Office. Despacho no 38, Londres, 6 y 9- VII-1827.

79 GuILle, 1965, pp. 117-118.

80 Diario Mercantil de Cádiz, no 3.581 de 30-V-1826; nº 3.957de 1-VI-1827; n 4.210 de 1-II-1828. 


\section{BURDEOS Y LA PLATA MEXICANA}

Como comentábamos, los comerciantes que salieron de México tras la declaración de independencia decidieron colocar sus capitales en plazas europeas distintas de las españolas, debido al cambio más favorable que obtenían en ellas y al clima de inseguridad política que se vivía en la península. Algunos de estos, principalmente vascos, se instalaron en Burdeos a principios de los años veinte y desde esa plaza procedieron a controlar muy pronto una buena parte de las relaciones mercantiles entre México y Francia, gracias a una bien articulada red de relaciones personales, configurada durante largos años de trabajo, con los comerciantes de las principales ciudades de México. Entre estos podemos señalar a los Ibarrondo, Aguirrebengoa, Íñigo, Ezpeleta, Escobedo o Pauzat de Zúñiga (quien sería más tarde cónsul mexicano en Burdeos) ${ }^{81}$.

De hecho, aunque el responsable de los negocios mexicanos en Burdeos lo negaba, las autoridades francesas estaban convencidas de que estos emigrados españoles de los años veinte controlaban ese mercado ${ }^{82}$. Lo que sí parece cierto es que estos negociantes conocían perfectamente este comercio y que sus consignatarios, la mayor parte españoles, establecidos en Veracruz, Tampico y en distintas plazas del interior de México, permanecieron colaborando y controlando todos los procesos de exportación de mercancías y plata al servicio de estas casas de comercio vasco-mexicanas instaladas en suelo francés ${ }^{83}$.

Los comerciantes españoles de México colocaban su dinero a disposición de estos negociantes españoles instalados en Burdeos, que guardaban el capital o lo invertían a gusto del cliente en una variedad de operaciones financiero-mercantiles. Asimismo se encargaban de cobros, pagos, transferencias, giros o ejercían de albaceas testamentarios por lo que estos negociantes cobraban un corretaje. Aunque la operación financiera más rentable para estos negociantes fue la amonedación en Burdeos de la plata que ellos mismos recibieron de México o la que recibían de allí como depositarios.

El gobierno galo fue uno de los primeros en entablar relaciones comerciales con México, permitiendo a partir de 1824 que los barcos mexicanos fueran admitidos en sus puertos, y desde 1827 Francia reglamentó en las relaciones comerciales con la nueva república. El agente del gobierno francés Alex Martin fue un testigo privilegiado de la salida de grandes cantidades de plata repatriada por los españoles entre los años 1823 y 1829 , que suponían a su entender "casi toda la fortuna de México" ${ }^{\text {. }}$.

La presencia de embarcaciones francesas en México es un claro indicador de cómo esta nación fue ocupando un lugar destacado en las relaciones comerciales con México. Así podemos observar cómo en 1823 tan solo un buque francés arribó en las costas mexicanas frente a los 15 ingleses. Dos años más tarde el número de naves franceses ya ascendía a 73, dos menos que las procedentes de Inglaterra, y finalmente en 1826 el comercio francés desplazó a Inglaterra con 54 barcos (en San Blas se

81 WeckmanN, 1961, exps. 2583 y 2587, pp. 155-156.

82 Carta de Galos a Tomás Murphy. Burdeos, 20-III-1829. Archivo Histórico Genaro Estrada (en adelante AHGE), doc. 2587.

83 AVIraneta, 1957, pp. 45-59.

84 Correspondencia Política, México, vol. II, exp.7. México, 12-VIII-1823. Archivo del Ministerio de Asuntos Exteriores de Francia (en adelante AMAEF). 
registró la entrada de tres barcos franceses de un total de 25 de otros países durante el primer trimestre de este año), 13 más que la flota inglesa. En relación al puerto de origen, destaca Burdeos con 25 buques, 13 El Havre, 11 de Marsella, 2 de Nantes y Bayona y 1 de Cète. Las relaciones comerciales franco-mexicanas alcanzaron un volumen importante para 1827 con la presencia en los puertos mexicanos de 55 barcos franceses con un volumen de 11.902 toneladas ${ }^{85}$, similar en cuantía y valor al de la metrópoli gala con sus colonias antillanas; y por parte mexicana este comercio supuso la tercera parte de su balanza exterior ${ }^{86}$.

Ese mismo año, el gobierno francés consideró imprescindible el establecimiento de una línea regular de vapores que hicieran la ruta Burdeos-Veracruz con una periodicidad mensual. De este modo, Francia se convertiría en el principal punto de llegada de expulsado y caudales españoles procedentes de México ${ }^{87}$.

En noviembre de 1827, pocos días antes de que el Congreso mexicano promulgase la primera ley de expulsión, el agente Martin informaba de la salida de cientos de españoles con destino a Burdeos llevando sus fortunas, tal como había sucedido con los más de 40 millones de pesos en plata desembarcados en el puerto bordelés en los últimos meses ${ }^{88}$, cifra que ha sido aceptada por muchos autores pero que a nuestro entender resulta exagerada ${ }^{89}$.

\subsection{La llegada de productos mexicanos a los puertos franceses}

Coincidiendo con la llegada en los primeros años veinte de emigrados españoles de México, el puerto de Burdeos se convirtió en el más importante de Francia entre estas dos naciones, seguido de los puertos de Marsella, Bayona y El Havre. En estas plazas se descargaron principalmente plata y oro, grana, maderas tintóreas, algodón, vaini1la, zarzaparrilla, fibras textiles, pecuarios y otros productos agrícolas ${ }^{90}$.

Pero fue la plata el producto mexicano más importante de los importados por Francia, plata que se cambiaba por moneda de curso legal francesa en las bancas departamentales de descuento de Burdeos, Nantes, Rouen y París ${ }^{91}$. De acuerdo con los datos aportados por Heers, la entrada de plata mexicana en el puerto de Burdeos, en relación con el total de las importaciones totales introducidas en Francia entre los años 1825 a 1827 , es como sigue (pesos) ${ }^{92}$ : en 1825 se introdujo plata por valor de 207.500 \$ (de los 468.750 \$ totales), un año más tarde fueron 270.000 \$ (del total de 575.000 \$) y en 1827 ascendió a $550.000 \$(\text { del total } 1.075 .000 \$)^{93}$.

Estas cifras vienen confirmadas por los datos recogidos en el Archivo Histórico Genaro Estrada, donde se puede comprobar que, entre octubre de 1826 y abril de 1830, llegaron a Burdeos procedentes de México 9.185.159 pesos en monedas de

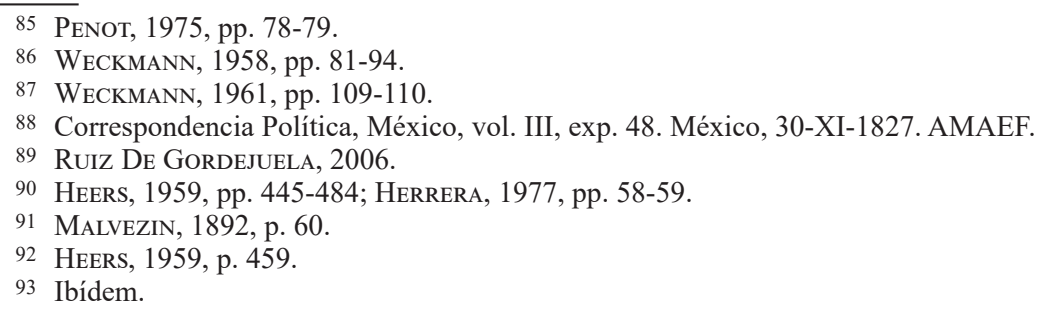

93 Ibídem. 
plata (54 millones de francos). A esa cantidad habría que sumar los más de 200.000 pesos llegados en plata labrada y los 2.283 .128 pesos en oro amonedado o labrado ${ }^{94}$.

Los registros mexicanos reflejan también cómo la salida de metales preciosos se fue incrementando con la década, hasta alcanzar su punto más alto en 1828 , cuando supuso el $80 \%$ de todas las exportaciones mexicanas, coincidiendo con el mayor flujo de expulsados españoles que cruzaron el océano ${ }^{95}$. Carlos $\mathrm{M}^{\mathrm{a}}$ Bustamante calculaba el capital español huido a este país en más de 34 millones de pesos ${ }^{96}$. De todas formas, la cantidad de plata mexicana que llegó de una u otra forma a Francia desde 1821 fue sin duda mucho mayor. La llegada de caudales americanos inquietó a los comerciantes franceses de Burdeos, que veían cómo la plata no llegaba precisamente como resultado de sus empresas comerciales en el continente americano, sino más bien de los caudales de los expulsos de México y al desaparecer el numerario en el país americano, la venta de productos franceses en México se frenaría de modo ostensible.

\section{CONCLUSIONES}

Este trabajo no ha pretendido cerrar este episodio, sino, más bien, es una invitación a que otros colegas maticen, corrijan o aporten avances que desarrollen este tema que consideramos de gran importancia en la historia atlántica. Todavía quedan aspectos por investigar como, por ejemplo, cómo repercutieron la plata y oro trasladados a $\mathrm{La}$ Habana procedente de México en el periodo previo al desarrollo azucarero cubano. De igual manera queda por desarrollar cómo estos caudales influyeron en la economía francesa e inglesa. No nos ha sido posible presentar avances en relación al grupo humano que conformó este conjunto de repatriados de México y que esperamos presentar en un futuro.

Hemos pretendido mostrar una visión más completa de la salida de la plata mexicana de propiedad española en un periodo de difícil estudio como son los años comprendidos entre la independencia de México y la primera ley de expulsión de españoles.

Las autoridades novohispanas y, posteriormente, las mexicanas permitieron que la plata de los españoles pudiera refugiarse en plazas como Cádiz, La Habana, Burdeos o Londres, a cambio de importantes impuestos. Somos conscientes que todavía existen elementos tan interesantes por estudiar en esta historia atlántica, como el volumen de metales preciosos que fueron embarcados en naves angloamericanas rumbo a los EE.UU.; la plata llegada a Gibraltar; o la plata y oro que salieron de México de modo ilegal, y de los que por desgracia no ha quedado rastro alguno.

Para los comerciantes españoles en tierras mexicanas, Londres se presentó como una plaza segura en donde colocar la plata por medio de una omnipresente armada británica, lejos de conflictos internos y medidas arbitrarias y cambiantes como la

94 Oficio n ${ }^{\circ}$ 1, Chauviteau Hermanos y Cía. a Mangino. Docs. 4848-4852. París, 23-IX-1832. AHGE.

95 Herrera, 1977, pp. 61-62.

96 La Voz de la Patria, 18-I-1829, p.1. 
española, en espera de vislumbrar en el futuro su destino definitivo. Asimismo, hemos comprobado la importancia de la salida de plata por el puerto de San Blas como parte de una geoestrategia mayor de defensa de los intereses británicos que también implicaba a los puertos del Callao, Guayaquil y Valparaíso, y todo ello bajo la custodia de su armada.

La correspondencia del comerciante vasco asentado en Cádiz Francisco de Carranza nos ha permitido conocer el modo en que se vivió la repatriación de capitales y personas, permitiéndonos esclarecer asuntos tales como ciertos caudales que llegaron bajo la consignación del rey, en realidad de particulares dirigidas a sus corresponsales. Asimismo, también presentamos cómo la quiebra londinense afectó a una gran parte de los capitales de los emigrados de México.

\section{REFERENCIAS BIBLIOGRÁFICAS}

AlamÁn, Lucas

1942 Historia de México. México. Jus, $3^{\text {a }}$ edición, 5 vols.

AvirAnETA, Eugenio de

1957 "Memoria sobre el estado actual del Reyno de Mégico y modo de pacificarlo". Boletín del Archivo Nacional de Cuba. La Habana, no 56, pp. 45-59.

Chávez Orozco, Luis

1966 El comercio exterior y la expulsión de los españoles. México. Publicaciones del Banco Nacional de Comercio Exterior.

CRUZ BARNeY, Óscar

2005 El comercio exterior de México 1821-1928. Sistemas arancelarios y disposiciones aduanales. México. UNAM.

2006 "El régimen jurídico del comercio exterior de México: de la independencia al tratado de libre comercio de América del Norte". Anuario Mexicano de Historia del Derecho. Vol XVIII. México DF, pp. 119-167.

DíAz, Luis Miguel - MARTini, Jaime G.

1977 Relaciones Diplomáticas México-España (1821-1977). México. Porrúa.

Florencio Puntas, Antonio

2002 "Patrimonios indianos en Sevilla en el siglo XIX: entre la tradición y la innovación". En Robledo Hernández - Casado Alonso (coords.), Fortuna y negocios: formación y gestión de los grandes patrimonios (Siglos XVI-XX). Valladolid. Secretariado de Publicaciones e Intercambio Editorial de la Universidad de Valladolid, pp. 191215.

Franco, José Luciano

1961 Documental para la Historia de México. La Habana. Publicaciones del Archivo Nacional de Cuba.

Gárate Ojanguren, Montserrat

1989 “Comercio exterior en el País Vasco (siglos XVIII-XIX)”. Historia Contemporánea. Universidad del País Vasco, nº 2, pp. 165-178.

2000 "Circuitos comerciales y financieros entre México y Europa (1800-1850): la participación vasca". En Yuste López - Souto MANTECón (coords.), El comercio exterior de México: 1713-1850. México. Instituto de Investigaciones Históricas - UNAM Universidad Veracruzana, pp. 223-259. 
Gough, Barry M.

1983 "Specie conveyance from the west coast of Mexico in British warships, c. 18201870. An Aspect of the Pax Britannica". The mariner's Mirror. United Kingdom, vol. 69, no 4, pp. 419-433.

Grajales, Gloria

1969 Guía de documentos para la Historia de México en archivos ingleses (siglo XIX). México. UNAM.

Guerra Vilaboy, Sergio

1998 "México y Cuba: primeros esfuerzos por la independencia cubana, 1820-1830". Sotavento. Bogotá, $\mathrm{n}^{\circ} 4$, pp. 32-45.

Guille, B.

1965 Histoire de la Maison Rothschild. Ginebra - París. Librairie Droz.

HeERs, Jacques

1959 "Les relations comerciales entre la France et le Méxique au lendemain de l'indépendance". Revista de Historia de América. México, no 48, pp. 445-484.

HERRERA, Inés

1977 El comercio exterior de México 1821-1875. México. El Colegio de México.

HuMPHREYS, R.H.

1940 British Consular Reports on the trade and politcs of Latin America, 1824-1826. London. Offices of The Royal Historical Society.

JimÉNEZ CoDINACH, Guadalupe

1998 "Veracruz, almacén de plata en el Atlántico. La casa Gordon y Murphy, 1805-1824". Historia Mexicana. México, vol. XXXVIII, nº 2 (oct.-dic.), pp. 325-353.

LADD, Doris M.

1984 La nobleza mexicana en la época de la independencia, 1780-1826. México. FCE.

LYNCH, John

2008 Las revoluciones hispanoamericanas. Barcelona. Ariel.

Malvezin, Théophile

1892 Histoire du commerce de Bordeaux depuis les origines jusq'ua nos jours. Bordeaux. Imp. Nouvelle A. Bellier, vol. 4, XIX siècle.

Ortíz De la Tabla Ducasse, Javier

1978 Comercio exterior de Veracruz 1778-1821: crisis de dependencia. Sevilla. Escuela de Estudios Hispanoamericanos.

OrTIZ-Sotelo, Jorge

1998 "Peru and the British Naval Station (1808-1839)". St. Andrews, Escocia. Thesis Submitted for the Degree of PhD at the University of St. Andrews. En http://researchrepository.st-andrews.ac.uk/handle/10023/2958.

2005 Perú y Gran Bretaña: politica y economía (1808-1839), a través de los informes navales británicos. Lima. Asociación de Historia Marítima y Naval Iberoamericana - Instituto de Estudios Internacionales - Pontificia Universidad Católica del Perú.

PENOT, Jacques

1975 Primeros contactos diplomáticos entre México y Francia 1808-1838. México. Colección del Archivo Histórico Diplomático Mexicano de la Secretaría de Relaciones Exteriores. 
Pinzón Ríos, Guadalupe

2008 "Una descripción de las costas del Pacífico novohispano del siglo XVIII". Estudios de Historia Novohispana. México, vol. 39, julio-diciembre, pp. 157-182.

PlatT, Desmond Cristopher Martin

1982 “Las finanzas británicas en México, 1821-1867”. Historia Mexicana. México, n 32 (2), pp. 226-261.

Román Alarcón, Rigoberto Arturo

1998 El comercio en Sinaloa, siglo XIX. México. Dirección de Investigación y Fomento de Cultura Regional - CONACULTA.

Ruiz De Gordejuela Urquijo, Jesús

2006 La expulsión de los españoles de México y su destino incierto, 1821-1836. Madrid. CSIC - Universidad de Sevilla - Diputación de Sevilla.

Sims, Harold Dana

1974 La expulsión de los españoles de México, 1821-1828. México. FCE.

1982 Descolonización en México. El conflicto entre mexicanos y españoles (1821-1831). México. FCE.

Smith, Roberts

1947 “José María Quirós: balanza del comercio marítimo de Veracruz e ideas económicas”. El Trimestre Económico. México, vol. 13, nº 52 (4) (enero-marzo), pp.680-711.

SOLÀ PARERA, Àngels

1985 "La independencia mexicana y la salida de capitales de españoles residentes en México (1810-1830)". En González Portilla - Maluquer de Motes - Riquer PerMANYER (eds.), Industrialización y nacionalismo: análisis comparativos. Actas del I Coloquio Vasco-Catalán de Historia. Barcelona. Servicio de Publicaciones de la Universidad Autónoma de Barcelona, Bellaterra, pp. 339-353.

Tenenbaum, Bárbara A.

1985 México en la época de los agiotistas 1821-1857. México. FCE.

1998 "Sistema tributario y tiranía: las finanzas públicas durante el régimen de Iturbide, 1821-1823”. En JÁUREGUI - SERRANO ORTEGA (coords.), Las finanzas públicas en los siglos XVIII-XIX. México. Instituto de Investigaciones doctor José María Luis Mora - El Colegio de Michoacán - El Colegio de México - UNAM, Instituto de Investigaciones Históricas.

TORRE VILlaR, Ernesto

1957 Correspondencia diplomática franco-mexicana 1808-1839. México. El Colegio de México.

Trejo Barajas, Dení

2014 "Pugna por el libre comercio en las postrimerías del virreinato: la Nueva Galicia y las Provincias Internas frente a los comerciantes de la ciudad de México, 1811-1818”. Estudios de Historia Novohispana. México, n 51 (julio-diciembre), pp. 107-130.

Trujillo Bolio, Mario

2009 El péndulo marítimo-mercantil en el Atlántico novohispano (1798-1825): comercio libre, circuitos de intercambio, exportación e importación. México. Publicaciones de la Casa Chata.

WARD, Henry G.

1981 México en 1827. México. FCE. 
WECKMANN, Luis

1958 "Un gran archivo histórico mexicano en París”. Historia Mexicana. México, vol. VIII, $n^{\circ} 1$, pp. 81-94.

1961 Las relaciones franco-mexicanas (1823-1867). México. Secretaría de Relaciones Exteriores, 2 vols. 